\title{
Who Becomes a High Utilizer? A Case-Control Study of Older Adults in the USA
}

\author{
Grant M. Smith, $M D^{7}$, Irena Stijacic Cenzer, $M S^{2,3}$, Kenneth Covinsky, $M D^{2,3}$, \\ David B. Reuben, $M D^{4}$, and Alexander K. Smith, MD, $\mathrm{MPH}^{2,3}$
}

\begin{abstract}
'Division of Palliative Medicine, Department of Medicine, University of California, San Francisco, San Francisco, CA, USA; ${ }^{2}$ Division of Geriatrics, Department of Medicine, San Francisco VA Medical Center, University of California, San Francisco, San Francisco, CA, USA; ${ }^{3}$ San Francisco Veterans Affairs Health Care System, San Francisco, CA, USA; 'Division of Geriatrics, David Geffen School of Medicine at UCLA, Los Angeles, CA, USA.
\end{abstract}

J Gen Intern Med 35(2):596-8 DOI: $10.1007 / \mathrm{s} 11606-019-05331-w$

(c) Society of General InternalMedicine (This is aU.S. government work and not under copyright protection in the U.S.; foreign copyright protection may apply) 2019

\section{INTRODUCTION}

Frequently hospitalized patients represent a high-cost population at risk of poor outcomes. These high-utilizers represent only $1.6 \%$ of admitted patients, but they account for $8 \%$ of admissions and $7 \%$ of direct costs. ${ }^{1,2}$ While prior studies have identified risk factors for 30-day readmissions, ${ }^{3}$ little is known about risk factors associated with patients who accrue multiple admissions over a longer period of time. Prior studies using cross-sectional analyses have also neglected to identify upstream risk factors for becoming a high-utilizer. ${ }^{3,4}$ Proactively identifying patients years before entering a cycle of frequent hospitalizations may allow for early intervention to prevent hospitalizations and improve outcomes. We sought to identify distinguishing comorbid conditions, functional limitations, and social risk factors that differentiate patients, who had 5 or more hospitalizations over a 2-year period, years before they became high-utilizers.

\section{METHODS}

We identified cases from the Health and Retirement Study (HRS) who reported having 5 or more hospitalizations over the past 2 years in a biannual survey between 2002 and 2014. We used the first survey on which high-utilizers reported 5 or more hospitalizations over 2 years as the index survey $\left(T_{0}\right)$ to identify cases. Each high-utilizer was matched to a control, who never reported being hospitalized 5 or more times over 2 years, based on age, gender, and survey year using data from the index survey $\left(T_{0}\right)$.

Received May 17, 2018

Revised October 17, 2018

Accepted August 22, 2019

Published online November 25, 2019
We then compared variables about chronic conditions associated with 4- and 10-year prognosis, ${ }^{5}$ functional status, and social factors from the survey immediately preceding the index survey $\left(T_{-1}\right)$ using bivariate chi-squared tests and conditional logistic regression. To compare the prevalence of risk factors over time, we used generalized linear mixed models using data from the index survey $\left(T_{0}\right)$ and the two surveys preceding the index survey $\left(T_{-1}\right.$ and $\left.T_{-2}\right)$, which provided three timepoints for comparison of change in prevalence. The institutional review board at the University of California, San Francisco, approved the use of data from HRS for this study.

\section{RESULTS}

Of the 18,602 participants age 65 and older, 984 (5.3\%) reported being admitted to the hospital 5 or more times within 2 years. Of those, $886(90.0 \%)$ had data from the prior two surveys and could be matched with controls on age, gender, and survey year, giving a sample of 1772 participants. In the first year of high utilization, high-utilizers reported a mean of 7.2 hospitalizations over 2 years (median 6, interquartile range (IQR) 5-8, range 5-75), while controls reported a mean of 0.6 hospitalizations over 2 years (median 0 , IQR $0-1)(p<0.001)$.

Comparing high-utilizers to controls using data from the survey immediately preceding the index survey $\left(T_{-1}\right)$, cases who became high-utilizers, had a higher prevalence of all comorbidities other than abnormal body mass index (BMI) and a higher prevalence of all examined markers of impaired function (Table 1). Cases also had higher prevalence of being not married or widowed and having an informal caregiver (Table 1).

A subset of factors had significantly different rates of change in prevalence over time between high-utilizers and controls. Factors with significantly different rates of change in prevalence included heart disease, BMI, impairments in activities of daily living (ADLs), impairments in instrumental activities of daily living (IADLs), falls, ability to drive, and difficulty climbing one flight of stairs (Fig. 1). None of the social factors or other medical conditions had significant differences in rate of change in prevalence. 
Table 1 Risk Factors of Cases and Controls 2 Years Prior to High-Utilizer Cohort Becoming Frequently Hospitalized $\left(T_{-1}\right)$

\begin{tabular}{|c|c|c|c|c|}
\hline Characteristic & $\begin{array}{l}\text { Cases }(N=886) \\
\text { No. }(\%)\end{array}$ & $\begin{array}{l}\text { Controls }(N=886) \\
\text { No. }(\%)\end{array}$ & Unadjusted OR & $P$ value \\
\hline \multicolumn{5}{|l|}{ Demographics } \\
\hline Age & $\begin{array}{l}\text { Mean } 74.9 \\
\text { SD }(7.9)\end{array}$ & $\begin{array}{l}\text { Mean } 74.9 \\
\text { SD }(8.0)\end{array}$ & 1 & \\
\hline \multicolumn{5}{|l|}{ Gender } \\
\hline \multicolumn{5}{|l|}{ Ethnicity } \\
\hline White & $674(76.1)$ & $681(76.8)$ & 1 & \\
\hline African American & $132(14.9)$ & $123(13.9)$ & $1.1(0.8-1.4)$ & 0.54 \\
\hline Latino & $62(7.0)$ & $68(7.7)$ & $0.9(0.6-1.3)$ & 0.67 \\
\hline Other & $18(2.0)$ & $14(1.6)$ & $1.3(0.6-2.6)$ & 0.47 \\
\hline \multicolumn{5}{|l|}{ Comorbidities } \\
\hline Number of hospitalizations & $2.2(8.3)$ & $0.5(0.9)$ & $1.9(1.7-2.1)$ & $<0.001$ \\
\hline Heart problems & $496(56.1)$ & $265(30.0)$ & $2.8(2.3-3.5)$ & $<0.001$ \\
\hline Lung disease & $209(23.7)$ & $74(8.4)$ & $3.2(2.4-4.2)$ & $<0.001$ \\
\hline Cancer & $198(22.5)$ & $136(15.4)$ & $1.6(1.3-2.1)$ & $<0.001$ \\
\hline \multirow{2}{*}{\multicolumn{5}{|c|}{ BMI }} \\
\hline & & & & \\
\hline Normal (18.5-24.9) & $263(30.1)$ & $292(33.3)$ & 1 & \\
\hline Underweight $(<18.5)$ & $23(2.6)$ & $22(2.5)$ & $1.1(0.6-2.0)$ & 0.71 \\
\hline Overweight/obese $(\geq 25)$ & $588(67.3)$ & $564(64.2)$ & $1.2(0.9-1.4)$ & 0.18 \\
\hline \multicolumn{5}{|l|}{ Functional status } \\
\hline \multicolumn{5}{|l|}{ ADL dependent } \\
\hline 0 dependent & $676(77.4)$ & $801(91.0)$ & 1 & \\
\hline $1-2$ dependent & 119 (13.6) & $53(6.0)$ & $2.9(2.0-4.3)$ & $<0.001$ \\
\hline \multirow{2}{*}{\multicolumn{5}{|c|}{ IADL dependent }} \\
\hline & & & & \\
\hline 0 dependent & $469(52.9)$ & $631(71.2)$ & 1 & \\
\hline $1-2$ dependent & $277(31.3)$ & 189 (21.3) & $2.2(1.7-2.8)$ & $<0.001$ \\
\hline$\geq 3$ dependent & $140(15.8)$ & $66(7.5)$ & $3.2(2.3-4.5)$ & $<0.001$ \\
\hline \multicolumn{5}{|l|}{ Self-rated health compared with last year } \\
\hline Better/about the same & $457(51.7)$ & $636(69.8)$ & 1 & \\
\hline Worse & $427(48.3)$ & $250(28.2)$ & $2.4(1.9-2.9)$ & $<0.001$ \\
\hline Visual impairment & $322(36.4)$ & $213(24.1)$ & $1.8(1.5-2.3)$ & $<0.001$ \\
\hline Hearing impairment & $301(34.1)$ & $228(25.7)$ & $1.5(1.2-1.9)$ & $<0.001$ \\
\hline \multicolumn{5}{|l|}{ Falls } \\
\hline None & $407(50.1)$ & $558(68.5)$ & 1 & \\
\hline $1-2$ & $116(14.3)$ & $108(13.3)$ & $1.5(1.1-2.1)$ & 0.009 \\
\hline $2-3$ & 94 (11.6) & $68(8.3)$ & $1.9(1.3-2.7)$ & 0.001 \\
\hline$\geq 3$ & $195(24.0)$ & $81(9.9)$ & $3.3(2.4-4.5)$ & $<0.001$ \\
\hline \multicolumn{5}{|l|}{ Driving status } \\
\hline No/never drove & $273(33.9)$ & $167(20.5)$ & 1 & \\
\hline Yes & $531(66.0)$ & $647(79.5)$ & $0.4(0.3-0.6)$ & $<0.001$ \\
\hline Difficulty climbing one flight of stairs & $427(48.4)$ & $219(24.7)$ & $2.8(2.3-3.5)$ & $<0.001$ \\
\hline \multicolumn{5}{|l|}{ Social factors } \\
\hline \multicolumn{5}{|l|}{ Alcohol use } \\
\hline$\leq 7$ & $763(86.2)$ & $714(81.0)$ & 1 & \\
\hline$\overline{7}-14$ & $49(5.5)$ & $72(8.2)$ & $0.6(0.4-0.9)$ & 0.02 \\
\hline$>14$ & $73(8.3)$ & $96(10.9)$ & $0.7(0.5-1.0)$ & 0.04 \\
\hline Informal caregiver & $172(19.4)$ & $66(7.5)$ & $3.1(2.3-4.3)$ & $<0.001$ \\
\hline \multicolumn{5}{|l|}{ Living children in contact } \\
\hline$\geq 2$ & $742(85.2)$ & $732(84.0)$ & 1 & \\
\hline$\overline{0}-1$ & $129(14.9)$ & $139(16.0)$ & $0.9(0.7-1.2)$ & 0.38 \\
\hline Living alone & $274(30.9)$ & $242(27.3)$ & $1.2(1.0-1.5)$ & 0.08 \\
\hline Financial assistance from children & $63(7.5)$ & $52(6.2)$ & $1.0(0.9-1.1)$ & 0.37 \\
\hline \multicolumn{5}{|l|}{ Marital status } \\
\hline Married & $449(50.7)$ & $540(61.0)$ & 1 & \\
\hline Not married/widowed & $436(49.3)$ & $346(39.1)$ & $1.7(1.3-2.1)$ & $<0.001$ \\
\hline
\end{tabular}

\section{DISCUSSION}

Our findings demonstrate that high-utilizers have a higher prevalence of comorbidities and higher rates of functional impairment compared with their age- and gender-matched peers years before they become high-utilizers. In addition, impairments of functional status more consistently showed greater increases in prevalence as cases moved closer to becoming high-utilizers. Together, these findings highlight the need to focus on preventive strategies that monitor, maintain, and improve function in addition to disease-specific models that may miss critical changes in function that are associated with frequent hospitalization. This study also adds to the literature by investigating a unique population who accrue multiple hospitalizations outside of 30-day readmissions and by investigating risk factors years upstream from high utilization. Future studies may further delineate the relationship between functional decline and the timing and duration of hospitalizations by linking HRS and Medicare data, which may reduce confounding factors present in this study. 


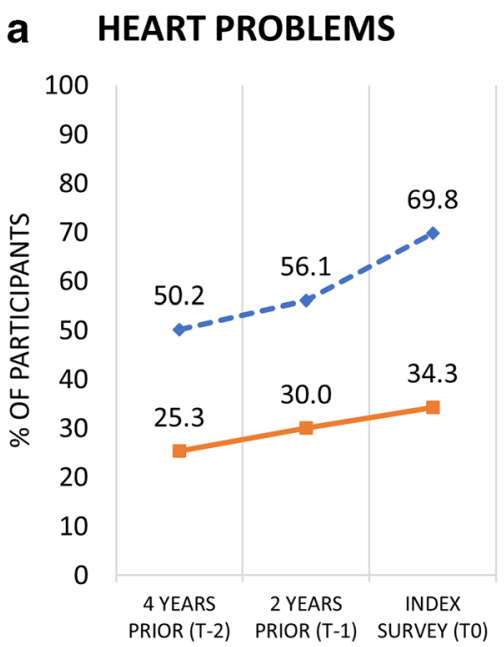

\section{3 OR MORE FALLS}

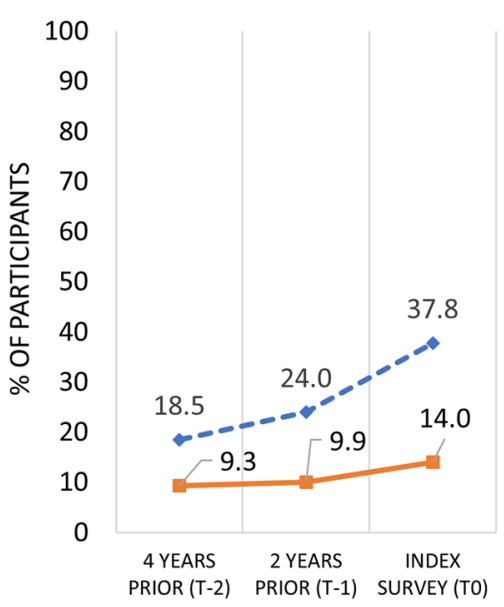

b 3 OR MORE DEPENDENT ADLS

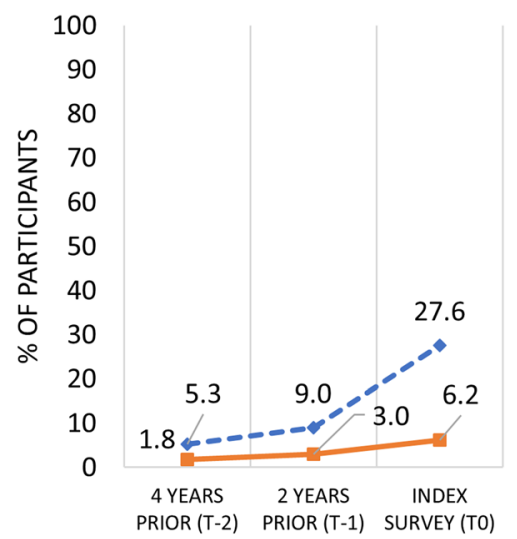

\section{d DIFFICULTY CLIMBING FLIGHT OF STAIRS}

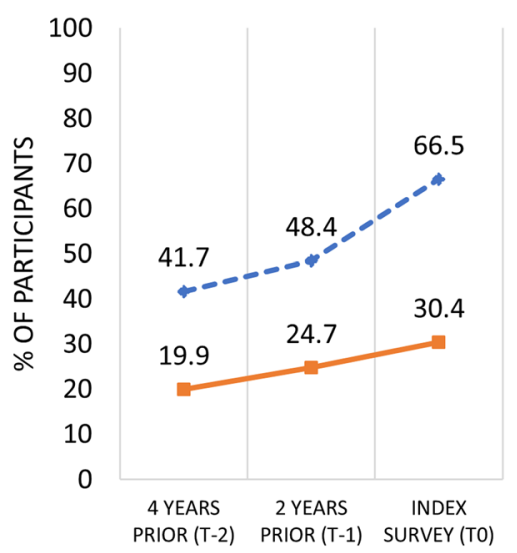

Figure 1 Change in prevalence of risk factors associated with frequent hospitalization over time. Comparison of the prevalence of comorbid conditions and functional limitations between participants who became frequently hospitalized at the time of the index survey (dashed horizontal line) and participants who were never frequently hospitalized (solid line). The comparisons of slopes are based on an overall line of best fit using mixed methods linear modeling. a Self-reported comorbid heart problems $(p=0.006)$. b Self-reported dependency for 3 or more activities of daily living $(p<0.001)$. c Self-reported 3 or more falls over the past 2 years $(p<0.001)$. d Self-reported difficulty climbing stairs $(p<$ 0.001).

Corresponding Author: Alexander K. Smith, MD, MPH; Division of Geriatrics, Department of Medicine, San Francisco VA Medical Center, University of California, San Francisco, San Francisco, CA, USA (e-mail: aksmith@ucsf.edu).

Funding Information Dr. Alex Smith and Dr. Grant Smith were supported by a grant from the National Institute on Aging (RO1AG047897).

\section{Compliance with Ethical Standards:}

The institutional review board at the University of California, San Francisco, approved the use of data from HRS for this study.

Conflict of Interest: The authors declare that they do not have a conflict of interest.

\section{REFERENCES}

1. Reuben DB, Tinetti ME. The hospital-dependent patient. N Engl J Med 2014;370:694-7.

2. Szekendi MK, Williams MV, Carrier D, Hensley L, Thomas S, Cerese J. The characteristics of patients frequently admitted to academic medical centers in the United States. J Hosp Med 2015; 10:563-8.

3. Kansagara D, Englander $\mathbf{H}$, Salanitro A, et al. Risk prediction models for hospital readmission: a systematic review. JAMA 2011;306:1688-98.

4. Jencks SF, Williams MV, Coleman EA. Rehospitalizations among patients in the Medicare fee-for-service program. N Engl J Med 2009;360:1418-28.

5. Lee SJ, Lindquist $\mathbf{K}$, Segal MR, Covinsky KE. Development and validation of a prognostic index for 4-year mortality in older adults. JAMA 2006;295:801-8.

Publisher's Note Springer Nature remains neutral with regard to jurisdictional claims in published maps and institutional affiliations. 